\title{
REVIEW \\ Progress of Rural Aquatic Ecosystem Analysis using Stable Isotope Ratios in Japan
}

\author{
Atsushi MORI ${ }^{1 *}$, Keiji WATABE ${ }^{1}$, Noriyuki KOIZUMI ${ }^{1}$ and \\ Takeshi TAKEMURA ${ }^{2}$ \\ ${ }^{1}$ Renewable Resources Engineering Research Division, NARO National Institute for Rural \\ Engineering (Tsukuba, Ibaraki 305-8609, Japan) \\ ${ }^{2}$ Rural Development and Planning Research Division, NARO National Institute for Rural Engineering \\ (Tsukuba, Ibaraki 305-8609, Japan)
}

\begin{abstract}
Land improvements in Japan involve the need to conserve ecosystems and biodiversity, hence research and research methods related to ecosystem conservation in rural aquatic areas are increasing and developing. Analysis in rural aquatic ecosystems using stable carbon and nitrogen isotope ratios is an important research method and such isotope ratios are used for various purposes when investigating rural ecosystems. Several characteristics of rural ecosystems have been found by stable isotope ratio analysis in Japan as described below. Food webs in drainage canals are derived from organic matter, comprising a mixture of algae and detritus attached to stones, whereas food webs in ponds originate from fallen leaves. In this study, it emerged that small food webs are sustained by various sources of materials in rural ecosystems. Quantitative results showed that most Japanese brown frogs move to secondary forests, where they feed and overwinter after metamorphosis or spawning. Micro food webs of web-building spiders differ from epigeal spiders because the carbon sources differ in terms of the secondary forest and levees, while the diversity of material flow in creatures of secondary forest ditches and the eco-tone between secondary forests and paddy fields was revealed by analyzing carbon stable isotope ratios. Analyzing stable isotope ratios in frogs indicates that frog populations include immigrants. Immigrants in reconstructed concrete canals cannot enter a new population, while the existence of immigrants in the population is evidence of dropping, washing and landing of frogs. This method can significantly boost the conservation of rural ecosystems by revealing the life processes of animals that are not well known.
\end{abstract}

Discipline: Agricultural environment

Additional key words: biodiversity, land improvement, material flow, paddy

\section{Introduction}

There are growing global concerns over the conservation of ecosystems and biodiversity and while crises undoubtedly tend to be linked to the ecosystems of tropical rainforests and the sea, they also exist in rural ecosystems of temperate climate zones. Disruption of rural ecosystems is caused by numerous factors, particularly agricultural development, despite the fact this improves agricultural productivity. In Japan, rural ecosystems have deteriorated in recent years due to factors such as rural development, modern agricultural techniques using chemical pesticides, land improvements, etc.

Land improvement in Japan comprises irrigation, drainage, land reclamation and other projects implemented under the Land Improvement Law and funded by national and prefectural governments. Farm land consolidation is one major land improvement project, which includes constructing terminal irrigation canals, terminal drainage canals, underground drainages, readjusting land and farm roads. Irrigation projects cover the main irrigation canals while farmland consolidation projects cover the terminal canals. Agricultural productivity is increasing due to these projects, and significantly boosting national, local and farm household economies. However, rural areas are also adversely affected because of the frequent use of concrete in modern technology, despite its severe effect on wild living organisms.

Recently, environmentally aware provisions in the

*Corresponding author: e-mail mori37@affrc.maff.go.jp

Received 18 December 2013; accepted 22 April 2014. 
form of land improvements have proliferated and spawned the construction of eco-friendly facilities throughout Japan. Of course, a basic understanding of rural ecosystems and animal biology is crucial to effectively accomplish this national mission. However, little is known about the ecosystems, especially in rural areas. Relatively new methods using stable isotope ratios can help researchers in Japanese rural ecology, and bolster traditional field observations, which still tend to underpin ecosystem research. Ecosystem analysis using isotope ratios has been studied in the sphere of lakes, inner bays, etc. However, this method was not applied to paddy field ecosystems until about a decade ago. In this paper, we report on the use of stable isotope ratios in Japanese paddy fields and include a reanalysis of previously reported research content(Mori 2012).

\section{Biological analysis using stable isotope ratios}

Isotopes of elements that do not emit radiation are labeled as stable - e.g. Carbon-13 and Nitrogen-15 isotopes often used to analyze food webs. These isotopes inevitably exist in nature, as well as in the bodies of living organisms. The stable isotope ratios of carbon and nitrogen are expressed as $\delta^{13} \mathrm{C}$ and $\delta^{15} \mathrm{~N}$, respectively.

The stable isotope ratio is defined with the following formula:

$$
\delta=\frac{\mathrm{R}_{\text {sample }}-\mathrm{R}_{\text {standard }}}{\mathrm{R}_{\text {standard }}} \times 1000(\%)
$$

$\delta$ : Carbon stable isotope ratio: $\delta^{13} \mathrm{C}$

Nitrogen stable isotope ratio: $\delta^{15} \mathrm{~N}$

$\mathrm{R}_{\text {standard }}$ : ; Carbon stable isotope ratio of Belemnites in PD-stratum, South Carolina

$\mathrm{N}$; Nitrogen stable isotope ratio of Nitrogen gas in the air $\mathrm{R}_{\text {sample: }}$ : Stable isotope ratio of sample, ${ }^{13} \mathrm{C} /{ }^{12} \mathrm{C},{ }^{15} \mathrm{~N} /{ }^{14} \mathrm{~N}$

Stable isotopes are used for ecosystem analyses (Peterson \& Fry 1987). Plants are classified into three groups by photosynthetic mechanisms, namely $\mathrm{C}_{3}, \mathrm{C}_{4}$ and CAM, although few species in the paddy fields of Japan belong to the latter group. A considerable number of plants in Japanese paddy areas are of the $\mathrm{C}_{3}$ variety, as are all trees in secondary forests. Conversely, sugarcane, corn, eulalia, crabgrass and giant foxtail are $\mathrm{C}_{4}$ plants, which can often be found in the periphery of paddy fields and are usually members of Gramineae native to tropical regions.

The $\delta^{13} \mathrm{C}$ values for $\mathrm{C}_{4}$ plants are approximately $-13 \%$, but range from -15 to $-10 \%$. The $\delta^{13} \mathrm{C}$ values of organisms are considerably lower than $\mathrm{C}_{4}$ plants, approximately $-27 \%$; ranging from -35 to $-25 \%$. Values for algae in an environment that abounds with $\mathrm{CO}_{2}$ are $\mathrm{C}_{3}$ and $\mathrm{C}_{4}$ plants at approximately $-20 \%$ as shown by a previous investigation(Hamilton \& Lewis 1992). The type of plants present as producers in a food web can be predicted by analyzing $\delta^{13} \mathrm{C}$, since it

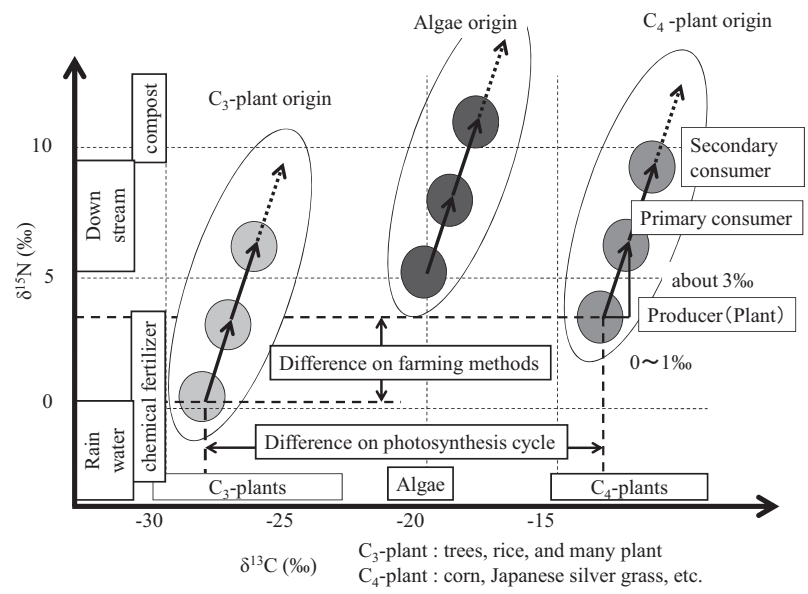

Fig. 1. $\delta^{13} \mathrm{C}-\delta^{15} \mathrm{~N}$ map representing the food web

changes little under prey-predator interactions. When the $\delta^{13} \mathrm{C}$ of an animal is approximately $-30 \%$, the animal is considered to be in a food web derived from $\mathrm{C}_{3}$ plants (Fig. 1).

\section{Characteristics of stable isotope ratios in rural areas of Japan}

Several characteristics are recognized in Japanese rural vegetation. One is mosaic botanical distributions such as paddy fields, fields, grasslands, orchards and secondary forests between mountains and lower zones where canals flow. These distributions are commonly found, even in an area of $1 \mathrm{~km}^{2}$. Only $\mathrm{C}_{3}$ plants are found in the secondary forest. Conversely, a significant proportion of plants near paddy fields are of the $\mathrm{C}_{4}$ variety, even though rice is a $\mathrm{C}_{3}$ plant. $\mathrm{C}_{4}$ plants often grow in terrestrial areas such as land which is temporarily fallow.

Algae are also important producers in rural ecosystems. $\delta^{13} \mathrm{C}$ differs between detritus and algae because most detritus in an agricultural drainage canal originates from litter produced in the secondary forest and paddy fields, where only $\mathrm{C}_{3}$ plants grow. Numerous aquatic animals feed on algae so this difference remains in the animals. Namely, the $\delta^{13} \mathrm{C}$ of animals feeding on detritus is lower than of animals feeding on algae. However, the value of fresh algae remains to be studied as herein described.

\section{Fresh knowledge obtained by previous investigative methods in Japan}

\section{Analysis of the food web}

Interactions among biological communities must be understood to conserve ecosystems. A major interaction in communities is certainly predation. As materials from animal bodies move from food to a predator, the characteristics of the producer plants are transferred to the animals. For example, the stable isotope ratio of an animal raised on $\mathrm{C}_{4}$ 
plants contains the approximate ratio of $\mathrm{C}_{4}$ plants. Food webs can be analyzed with carbon and nitrogen stable isotope ratios as described previously. An analysis of samples from rural areas is described below.

Samples were dredged from two aquatic areas, a drainage canal and a small irrigation pond, of the Isawa Plain located in Iwate prefecture, Tohoku district in 2005(Mori 2007). The canal featured an eco-friendly construction without a concrete bottom, but with a considerable mass of stones, earth and sand deposited. The pond was located on the boundary between the plain and a hill. Numerous leaves had fallen into it, leaving the water brownish-red; probably due to the elution of organic elements. Small tin cups were filled with pretreated samples, which were then defatted with methanol and chloroform and crushed. The stable isotope ratios of the samples were then analyzed with a mass spectrometer, Delta Plus XP, manufactured by Thermo Finnigan. Subsequent samples were all pretreated out in the same way.

Figure 2 shows the C-N map (food-web) of the canal. The $\delta^{13} \mathrm{C}$ values of the samples, key for distinguishing the food web, were approximately -25 to $-20 \%$, while the organic matter attached to stones was eaten by insects and fishes as shown by the continual increase in living matter. Microscopic visualization revealed this attached matter was detritus and algae. The values for the attached matter were consistent with detritus and algae, since they ranged between the $\delta^{13} \mathrm{C}$ for $\mathrm{C}_{3}$ plants and algae. The Amur Minnow (Phoxinus logowskii steindachneri), a Cyprinidae, was at the top of the food web. The minnow stomachs were filled with caddis-fly larvae, also confirming the results of stable isotope ratio analysis, because the insects fed on organic matter comprising detritus derived from terrestrial plants and algae.

Figure 3 shows how the values for the pond food web were lower than for the canal in Fig. 2. The food web in the pond clearly depends on $\mathrm{C}_{3}$ plants. The top of the pyramid is likely small insects, such as water boatman (Notonecta triguttata) that feed on the fluids of small fishes, tadpoles, insects, etc. This curious food web sometimes appears in an aquatic area that lacks fish. The results show that small food webs are sustained by various materials in a rural ecosystem. These various food webs can be regarded as reflecting the diversity of the ecosystem.

\section{Analysis of animal movement}

Using the behavior of stable isotope ratios described previously, the ecological characteristics of animals can be analyzed as well as food webs. The Japanese brown frog (Rana japonica) is a typical amphibian in rural areas, although its population is rapidly declining with the revamping of agricultural drainage canals. The prime reason for this decrease is presumably the concrete agricultural drain-

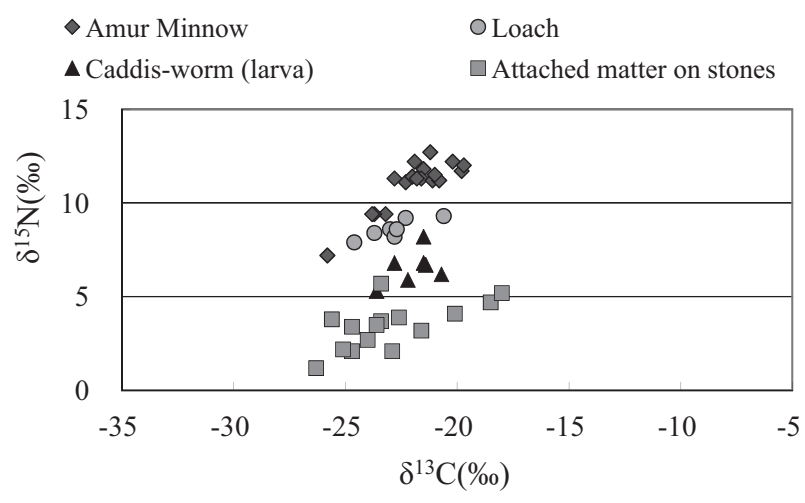

Fig. 2. $\delta^{13} \mathrm{C}-\delta^{15} \mathrm{~N}$ map of matter collected from a canal

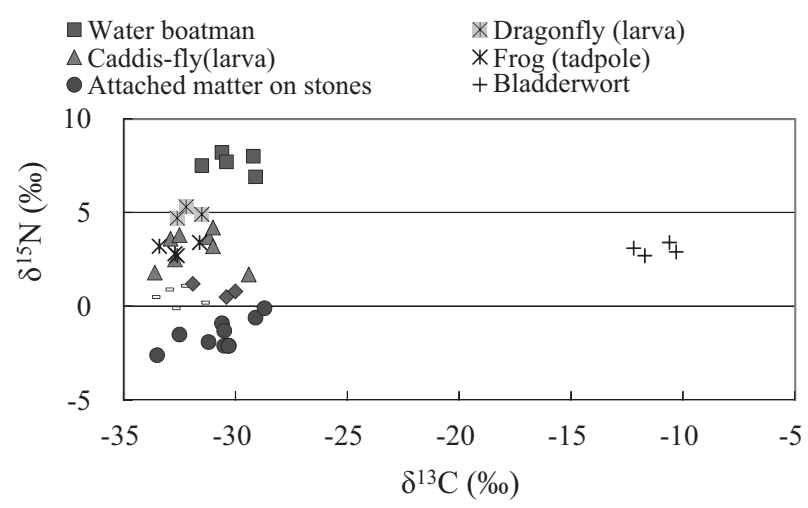

Fig. 3. $\delta^{13} \mathrm{C}-\delta^{15} \mathrm{~N}$ map of matter collected from a pond

age canals cutting networks between terrestrial and aquatic areas. Qualitative past knowledge indicates adult Japanese brown frogs live and overwinter in the secondary forest and after hibernating, move to the paddy fields to spawn. Indeed, while the secondary forest is an important habitat, such frogs are also often seen near paddy fields, land which is temporarily fallow, and levees. Since it is unclear whether the wintering places are only secondary forests, we must quantify how they move there.

Some $\mathrm{C}_{4}$ plants grow in land which is temporarily fallow, meaning frogs that feed there will have higher $\delta^{13} \mathrm{C}$ values than those that feed in the secondary forest exclusive to $\mathrm{C}_{3}$ plants. However, catching frogs is difficult because they are very agile and move to paddy fields overnight so we developed a way to collect data from the spawns.

Samples were collected from two paddy fields in a hilly and mountainous rural area of Tochigi prefecture, popular with frogs(Mori et al. 2008). Paddy field A borders a secondary forest on two sides, and fallow land on two sides. Field B borders a Satoyma on one side, fallow land on one side, and paddy fields on two sides. Over 100 egg masses were skimmed from each field with a dipper, and 20 eggs were collected from each egg mass. The eggs were defatted with methanol and chloroform, and then crushed. Stable isotope ratios of the samples were analyzed with a mass 
spectrometer, Delta plus XP, manufactured by Thermo Finnigan.

Figure 4 shows the analytical results of both paddies, where two peaks of the histogram emerge. One with a central value of $-25 \%$ indicates the mother frogs fed in the $\mathrm{C}_{3}$ environment, secondary forest. Another group existed with values from -21 to $-16 \%$ because their mothers consumed an appreciable amount of insects that fed on $\mathrm{C}_{4}$ plants. The results indicate that most Japanese brown frogs move to the secondary forest after metamorphosis or spawning, where they feed and overwinter. Anticipating the impact of land use on the movement patterns of frogs, we hypothesized the $\delta^{13} \mathrm{C}$ value for eggs in field A would exceed that of field $\mathrm{B}$ because field $\mathrm{A}$ bordered fallow fields where $\mathrm{C}_{4}$ plants grew. However, no considerable differences emerged between $\mathrm{A}$ and $\mathrm{B}$, showing that frogs move to the secondary forest at a constant rate.

Agricultural drainage canals are usually routed through boundary areas between paddy fields and secondary forests. However, most frogs that come to paddy fields for spawning fall into a concrete agricultural drainage canal from which they cannot escape. Conservation of frogs must be considered when canals are revamped to preserve their population. The problem is the lack of effective conservation methods. Slopes are often constructed in canal walls to help frogs escape. However, these are ineffective for sustaining frog populations, because amphibian biota severely deteriorate, even when conservation facilities are constructed. Capping the opening of canals is a good method, but costly and farmers reject this, since they cannot use the water to wash their farm tools. Some farmers also complain that capping causes the water temperature to rise, although this effect appears minimal. In summary, we quantitatively showed that most frogs try to cross canals so truly effective actions to save frog populations must be developed. Conservation measures to help small animals like frogs that fall into canals are crucial.

\section{Analysis of the ecosystem structure}

Paddy fields at a hill-bottom or elsewhere are called Yatsuda in Japanese and include paddy fields and secondary forests, as well as aquatic and terrestrial areas. Canals almost always run along the border area between paddy fields and secondary forests.

We focused on spiders to analyze food webs, since they are at the top of micro food webs. Spiders can be divided into two groups based on lifestyles, web-builders and hunters. Furthermore, we separated hunters into arboreal and epigeal spiders respectively, because each type consumes specific food depending on habitat.

In 2007, we analyzed the carbon stable isotope ratios $\left(\delta^{13} \mathrm{C}\right)$ of spiders (Arachnida) caught at nearby farm ditches and a levee in a paddy field at the hill-bottom (Yatsuda) in

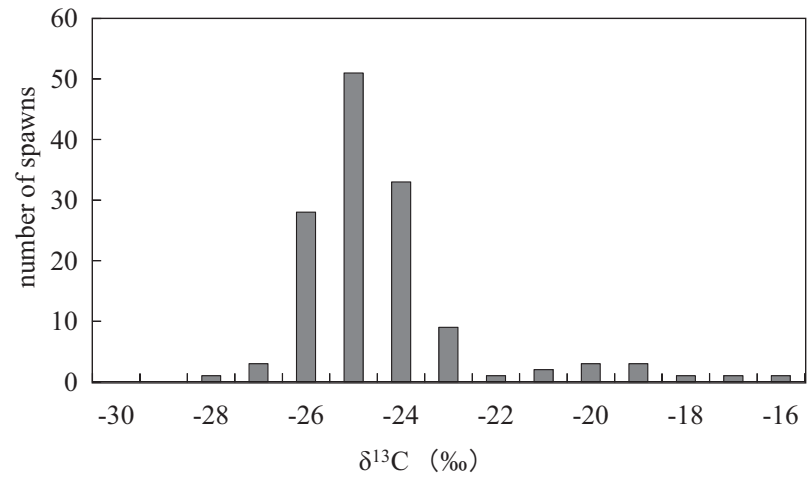

Fig. 4. Histogram of $\delta^{13} \mathrm{C}$ distribution of spawns (entirety)

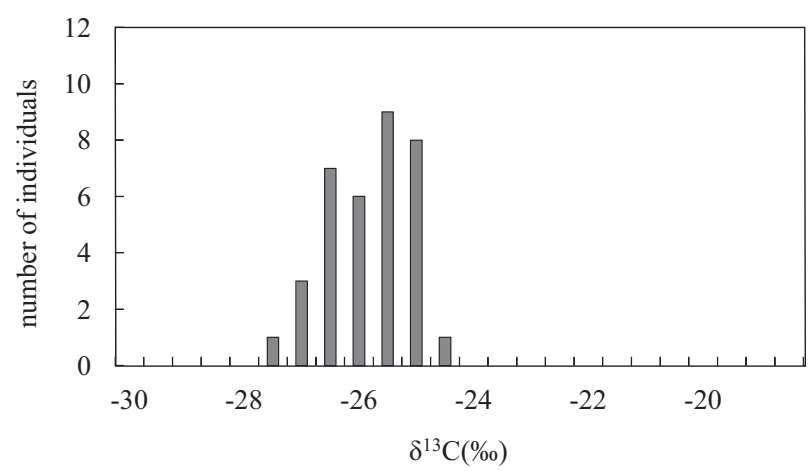

Fig. 5. Histogram of web-building spiders

Tochigi prefecture (Mori et al. 2007). The average $\delta^{13} \mathrm{C}$ of web-building spiders (Fig. 5) was $-26.0 \%$, indicating they are significantly affected by insects from ditches that depend on organic matter from the secondary forest, as determined by employing previous analyses of soil and fallen leaves from the secondary forest and ditches. The $\delta^{13} \mathrm{C}$ quantities and distribution of long-jawed water spiders (Tetragnatha maxillosa) were approximately equal to silver vlei spiders (Leucauge magnifica), suggesting that both spiders depend on the same food resources. The $\delta^{13} \mathrm{C}$ of epigeal spiders was $-22.2 \%$, indicating that $\mathrm{C}_{4}$ plants, grown only on the levee, increased the $\delta^{13} \mathrm{C}$ values of these spiders (Fig. 6). Namely, the micro food web of web-building spiders differs from epigeal spiders because the carbon flows are derived from different sources, the secondary forest and levee. The diversity of material flows in creatures of Yatsuda ditches, the eco-tone between secondary forests and paddy fields, was revealed by analyzing carbon stable isotope ratios (Fig. 7). Animals within a narrow area share food and are compartmentalized, which reflects the diversity of an ecosystem.

Canals in the boundary area between secondary forests and paddy fields are often consolidated when land improvement projects are implemented. Of course, new canals are almost always concreted after construction, whereupon the complex and diversified ecosystem is transformed into a homogeneous one. So the environment of canals needs to 


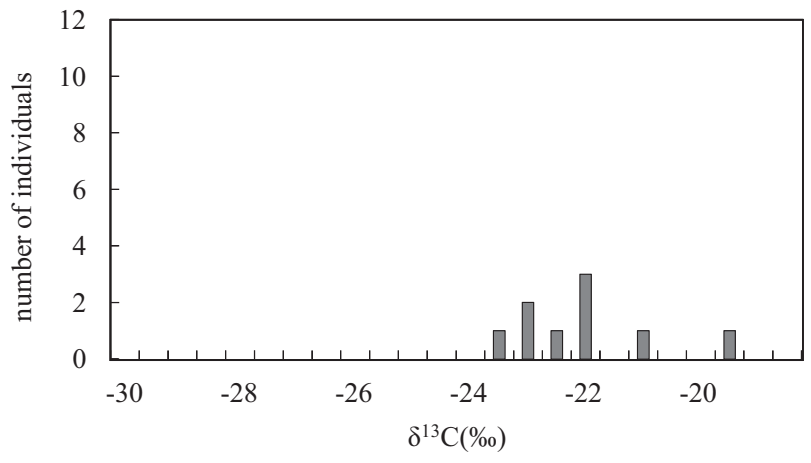

Fig. 6. Histogram of epigaeic hunting spiders

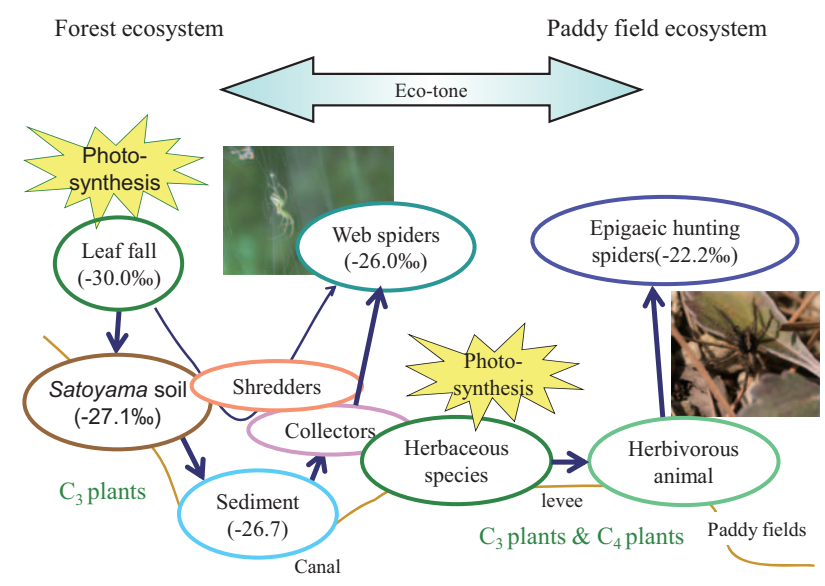

Fig. 7. Food web and carbon flow of spiders around canals in the Yatsuda area

be restored to some degree before canal ecosystem falls into catastrophic shift.

\section{Analysis of the population structure}

Whether populations of animals are homogeneous and how members move between populations are important means of understanding the population structure. Moreover, the constitution of a population is an important factor sustaining it, with complements that continue even if individuals decrease. Stable isotope ratios are often very helpful to understand the animal population structure.

Stable isotope ratios of animals show interesting behavior caused by differences in turnover time depending on body parts. Turnover times for muscles and stomach are relatively short, whereas that of bone is slower. If there is a difference between body parts, particularly bone and other parts, whether a frog has fed in a particular habitat in the past can be determined, because the carbon isotope ratios of the previous food will remain in the bone. This method can also reveal whether animals have lived in the same or different habitats.

The carbon isotope ratios of three body parts of the

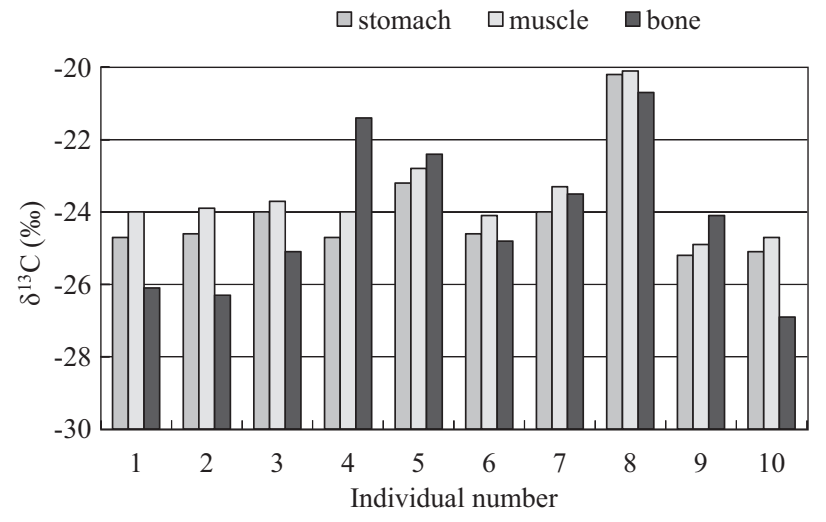

Fig. 8. Carbon isotope ratios from body parts of the Tokyo Daruma Pond Frog

Tokyo Daruma Pond Frog (Rana porosa porosa) caught at the Yatsuda area in 2008 were analyzed (Fig. 8, Mori et al. 2009), whereupon variability in internal body parts was observed within the population and certain individuals. Specifically, values of the bone of individuals 5 and 19 were lower than the muscle and stomach, which shows that the frogs grew in a different habitat where the carbon isotope ratio of the insect food differed from the area in which the frogs were caught. These frogs joined the population later, as indicated by the remaining value of carbon derived from the former food source in the bone. The overall values of individuals 6 and 10 differed from the majority of other individuals. The carbon isotope ratios of the body had not completely changed to the background value of the area in which they were caught (habitat of the population), indicating these individuals joined the group recently. Background values are also affected by the weighted average of the stable isotope ratio of the producer, namely, individual 6 may have grown up in an area with considerable $\mathrm{C}_{4}$ plants. Conversely, individual 10 may have grown up in an area with all $\mathrm{C}_{3}$ plants and fed on insects that depended almost exclusively on the same.

Based on these results, we can conclude that while individuals having moved from different habitats are also obviously important from the biological perspective, how immigrants join a population is also an important issue for conservation. Frogs live near paddy fields and canals, into which they jump when attacked by predators. Most frogs cannot escape from reconstructed canals and are washed away because of their inability to land on the canal walls, even downstream. In contrast, most frogs that jump into primitive canals can escape. Even though some frogs are washed downstream, they can eventually escape and join a new population. The existence of immigrants in populations is evidence of the dropping, washing and landing of frogs.

Canals play a role in the pathway of aquatic animals, 
not just in agricultural production. This investigation shows that breakpoints in aquatic networks have harmful effects; not only on the migration of fishes but also the movement of frogs from other populations. Immigrants most likely play key roles in the transfer of genes between populations.

\section{Implication for ecosystem conservation}

Food webs are complex, since the stable isotopes showed that complete conservation after land improvement projects was impossible. Comparatively effective improvements should be chosen and improved project plans which avoid homogeneous ecosystems are crucial. Environmental diversity is also needed to create a varied ecosystem, while retaining continuity in animal habitats is also an important concept for ecosystem conservation. It is true that continuity in a canal, namely longitudinal, has recently been a concern in projects, but the importance of transverse continuity between paddies and secondary forests is not realized well in projects. The need to avoid disassociation, transversely as well as longitudinally, must be considered and the risks of a population becoming extinct or seeing its genetic diversity deteriorate can be decreased by focusing on these two points.

\section{Conclusion}

Stable isotope ratios are used for various purposes when investigating rural ecosystems. Several characteristics of rural ecosystems were found through stable isotope ratio analysis in Japan as described below.

(1) Analysis of the food web

Food webs in a drainage canal are derived from organic matter, comprising a mixture of algae and detritus attached to stones, whereas those in ponds originate from fallen leaves. This study showed that small food webs are sustained by various sources of materials in the rural ecosystems.

(2) Analysis of animal movement

Quantitative results showed that most Japanese brown frogs move to secondary forests after metamorphosis or spawning, where they feed and overwinter.
(3) Analysis of the ecosystem structure

Micro food webs of web-building spiders differ from epigeal spiders because the carbon sources in the secondary forest and levees also differ. Diversity of material flow in creatures of Yatsuda ditches, the eco-tone between secondary forests and paddy fields, was revealed by analyzing carbon stable isotope ratios.

(4) Analysis of the population structure

Analysis of stable isotope ratios in frogs indicates that frog populations include immigrants, which cannot enter new populations when they fall into reconstructed concrete canals. The existence of immigrants in a population is evidence of the dropping, washing and landing of frogs, while using stable isotope ratios can significantly boost the conservation of rural ecosystems by revealing characteristics of animal lives that are not yet well known.

\section{References}

Hamilton, S. K. \& Lewis Jr., W. M. (1992) Stable carbon and nitrogen isotopes in algae and detritus from the Orinoco River floodplain, Venezuela. Geochimica et Cosmochimica Acta, 56, 4237-42461.

Mori, A. (2007) Behavior of Stable Isotope Ratios of Attached Matter in a Drainage Canal. Japan Agricultural Research Quarterly, 41, 133-138.

Mori, A. et al. (2007) Origin Estimation of Carbon of Spiders (Arachnida) by Carbon Stable Isotope Ratio. Nougyou Nouson kougakkai Ronbunsyu (Irrigation, Drainage and Rural Engineering Journal), 251, 565-571 [In Japanese with English summary].

Mori, A. et al. (2008) Estimation of Japanese Brown Frog Movement by Stable Isotope Ratio Method. $2008^{\text {th }}$ Lecture Meeting of The Japanese Society of Irrigation, Drainage and Rural Engineering, 700-701 [In Japanese].

Mori, A. et al. (2009) Organ Specific Carbon Stable Isotope Ratio of Tokyo Daruma Pond Frog. Nougyou Nouson kougakkai Ronbunshu (Irrigation, Drainage and Rural Engineering Journal), 261, 93-94 [In Japanese].

Mori, A. (2012) Analysis of rural ecosystem in Japan using stable isotope ratio. In Applied Photosynthesis, Intech, Croatia, 403-422.

Peterson, B. J. \& Fry, B. (1987) Stable isotopes in ecosystem studies. Annual Review of Ecology, Evolution, and Systematics, 18, 293-320. 